\title{
Causality between Financial Deepening and Economic Growth in Nigeria: Evidence from a Bootstrap Rolling Window Approach
}

\author{
Goodness C. Aye
}

\begin{abstract}
This paper investigates the role of financial development on economic growth in Nigeria. Since a causal link may evolve over time, a bootstrap rolling window approach is used to account for potential time variation in the relationship with annual Nigerian data on money supply as a ratio of nominal GDP and real GDP per capita from 1961-2012. Starting first with a full sample bootstrap Granger causality, the results indicate no causality between the two series. The relevant VAR is unstable for the full sample which undermines the confidence in the bootstrap full sample Granger causality tests. Therefore a bootstrap rolling window estimation was used to evaluate Granger causality between financial deepening and economic growth over different time periods. These tests reveal periods where financial deepening has predictive power for economic growth: 1973-1974 and 1976 as well as periods where economic growth has predictive power for financial deepening: 1980-1982, 1985-1986, 1995-1996, 1998, 2000, 2004 and 2008-2011. These results highlight the risk of misleading conclusions based on the standard Granger causality tests which neither accounts for structural breaks nor time variation in the relationship between financial deepening and economic growth.
\end{abstract}

Index Terms-Bootstrap, economic growth, financial deepening, time varying causality.

\section{INTRODUCTION}

In Nigeria, domestic output (GDP) growth has shown mixed developments between 1981 and 2012. During this period, the economy registered declines in the real GDP (at 1990 constant basic prices) in five years $(1982,1983,1984$, 1987 and 1991) ranging from -7.1 per cent in 1983 to -0.6 per cent in 1987. For the rest of the period, the annual real GDP growth was positive. The economy witnessed high growth rates of 10.2 and 10.5 per cent in 2003 and 2004 before declining to 6.0 per cent in 2008 , followed by a mild recovery of 6.7 per cent in 2009. From 2005 until 2013, Nigeria GDP annual growth rate averaged 6.8 percent reaching an all-time high of 8.6 percent in December of 2010 and a record low of 4.5 percent in March of 2009 and expanded 7.67 percent in the fourth quarter of 2013 over the same quarter of the previous year [1], [2].

Although, a number of factors could have contributed to the above scenarios, this study focuses on examining whether financial development may be a significant factor for economic growth in Nigeria given that several policies have

Manuscript received February 12, 2014; revised April 22, 2014.

Goodness C. Aye is with the University of Agriculture Makurdi, Nigeria, She is also with the University of Pretoria, South Africa (e-mail: goodness.aye@gmail.com). been implemented in an attempt to integrate financial services into growth objectives in Nigeria. Further, the global financial crisis has illustrated the potentially disastrous consequences of weak financial sector policies for financial development and their impact on the economic outcomes. The crisis has challenged conventional thinking in financial sector policies and has led to much debate on how best to achieve sustainable development. Nigerian financial market has been noted to be one of the largest in Sub-Saharan Africa with regard to diversity of institutions and instruments [3]. The Nigerian financial system can be broadly divided into two sub-sectors, namely: the informal and the formal sectors. The informal sector comprises the local money lenders, the thrifts, savings associations, etc. This component is poorly developed, limited in reach, and not integrated into the formal financial system. The formal financial system on the other hand can be further sub-divided into capital and money market institutions. It is made up of the banks and non-bank financial institutions. The system became liberalized in the 1980s when the structural adjustment program me was introduced. The system has undergone significant changes in terms of the policy environment, number of institutions, ownership structure, depth and breadth of markets, as well as in the regulatory framework. The financial system comprises of the central bank, commercial banks, mutual funds, brokerage firms, discount houses, and stock exchange, to mention just few. These institutions trade in financial instruments such as domestic currency, foreign currency, stocks, bonds, derivatives and so on, and in the process mobilize funds from surplus unit (savers) to deficit unit (investors). Although a wide variety of financial institutions and markets exist, commercial banks overwhelmingly dominate the financial sector and traditional bank deposits represent the major forms of financial saving. Therefore, the financial markets have been adjudged to be shallow when compared with advanced and emerging economies [3].

Theoretically, there exists some form of linkage between finance and economic growth. One of the oldest debates in economics has remained the relationship between financial development and economic growth. Its root can be traced to [4], when he posits that finance is paramount for economic growth. However, [5] argues that economic growth promotes financial development. Financial markets provide an economy with vital services comprising, for example, the management of risk and information, and the pooling and mobilization of savings [6]. Theoretically, the linkage between finance and economic growth may take different forms. On the one hand, the financial sector may affect growth through the accumulation channel and the allocation 
channel. The accumulation channel emphasizes the finance-induced growth effects of physical and human capital accumulation [7]. The allocation channel focuses on the financed-induced efficiency gains in resource allocation that enhances growth [8]. Following these considerations, causality runs from finance to growth (supply-leading hypothesis). On the other hand, financial development may also be stimulated by economic growth. For instance, in a growing economy, the private sector may demand new financial instruments and an improved access to external finance. Financial activities then simply expand in step with general economic development [5], positing the so-called demand-following hypothesis. Additionally, finance and growth may be mutually dependent. The real sector may provide the financial system with the funds necessary to enable financial deepening, eventually allowing for a capitalization on financial economies of scale which in turn facilitates economic development [9]. The latter hypothesis postulates bidirectional causality. Countries with better-developed financial systems are therefore expected to grow faster over long periods of time. Following more skeptical views [10], the financial and real sector may also be independent of each other, thereby naturally putting emphasis on other factors that may determine economic development (insignificant causation).

Empirically, a number of studies have examined the relationship between finance and growth (See [11], [12] and the literatures cited within). The results are often mixed resulting in some cases due to methodology used, proxy for financial development used and whether it is cross-country or country-specific study. As far as Nigeria is concerned, only few studies have examined these links. For instance, the link between finance and growth is examined by [13]-[20]. One of the major weaknesses of majority of these studies is that they investigated the relationship without considering the issue of causality or reverse causality. It is however widely accepted now that the existence of a relationship does not imply causality. Moreover, the causal connection between finance and growth has typically been investigated with standard Granger causality tests. But this method suffers from a number of limitations. For example, the test results are sensitive to the functional form in which the VAR or VECM is specified such as: the set of regressors, deterministic terms included, lag length, sample or observation window used as well as the treatment of integration and cointegration.

An additional problem arises from the assumption that the causal relationship between financial development and growth applies to every point in the whole sample. Both the standard Granger causality testing and different modified versions [6], [21], [22] suffer from this limitation. It is possible that the experience of any particular country could support a unidirectional causality during some periods, while providing bidirectional causality or even no casualty in yet further sub samples, i.e. the relationship could be time-varying. The motivation for this paper is to address this particular short-coming in the literature by re-examining the causal link between financial deepening and economic growth in Nigeria with a bootstrap full sample and subsample rolling window estimation approach. The rolling estimation with fixed window size is used and Granger non-causality test is applied on rolling subsamples of the data. To ensure robustness against sample size, stationarity and integration-cointegration properties of the data, the bootstrap causality test is used.

The remainder of the paper is organized as follows: section two describes the data and explains the empirical model used. Results are discussed in section three while section four concludes.

\section{DATA AND MODEL}

We use the entire historical annual time-series data, which covers the 1961 to 2012 periods. The ratio of broad money $(M 2)$ to nominal GDP is used as an indicator of financial deepening and is labelled $M 2 G D P$. For economic growth, the real GDP per capita is used and the series is labelled $R G D P P C$. Both variables are transformed into natural logarithms. The plot of the two series used is shown in Fig. 1. There appears to be strong comovement between $M 2 G D P$ and $R G D P P C$. However, this will be verified using the relevant tests as described below. Prior to investigating Granger causality, the stationarity of the data is tested using the Philips and Perron [23], [24], Augmented Dickey Fuller and $M Z_{\alpha}$ test of [25].

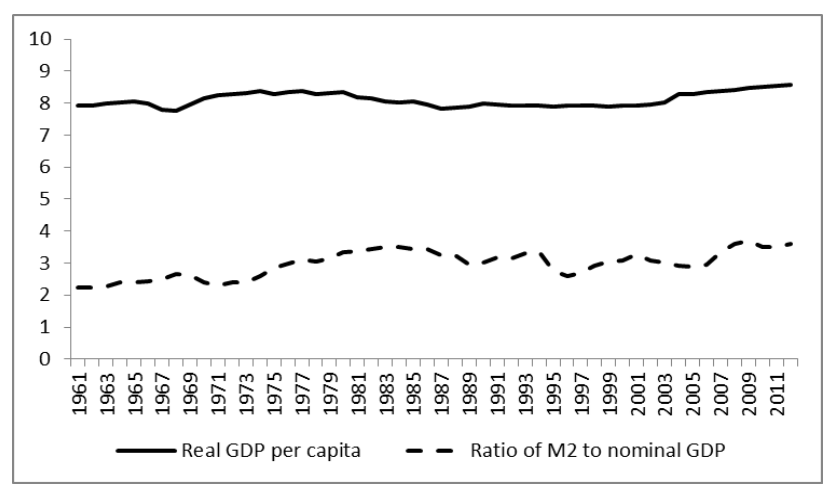

Fig. 1. Log of real GDP per capita and $\log$ of the ratio of $M 2$ to nominal GDP

The null hypothesis is Granger non-causality between financial deepening and economic growth. Granger non-causality occurs when the information set on the first variable (e.g., $M 2 G D P$ ) does not improve the prediction of the second variable (e.g., $R G D P P C$ ) over and above the predictive capacity of the information in the $R G D P P C$ time series. From a statistical perspective the Granger non-causality test is performed by examining the joint significance of lagged values for the first variable in a predictive model for the second variable that is usually embedded in a two-equation VAR model. In such a VAR framework the joint parameter restriction associated with the Granger non-causality test can be conducted with the Wald, Likelihood ratio $(L R)$ and Lagrange multiplier $(L M)$ statistics. But these test statistics are based on the assumption that the underlying data is stationary. With non-stationary data, as is typical in macroeconomic studies, these tests may not have standard asymptotic distributions. The difficulties that arise with inference in a VAR with non-stationary data have been shown by Park and Phillips [26]-[28], among others.

To address the problems of non-stationary underlying data, [29], [30] proposed a modification to the standard Granger 
causality test. Starting with a $\operatorname{VAR}(p)$, where $p$ is the lag order, and the data is integrated of the first order, the proposed method based on estimating a $\operatorname{VAR}(p+1)$ in the levels and they derived standard asymptotic distributions for the Granger causality test regardless of the integration-cointegration properties of the data. The method entails estimating a $\operatorname{VAR}(p+1)$ with the Granger non-causality test carried out on the first $p$ lags. Thus, one coefficient matrix, which relates to the $(p+1)^{\text {th }}$ lag, remains unrestricted under the null, giving the test a standard asymptotic distribution.

This paper builds on the [29], [30] modified test, but with an extension to use a residual based bootstrap $(R B)$ test rather than standard asymptotic tests. It is the outstanding performance (in terms of power and size) of the residual $R B$ method, irrespective of cointegration, that justifies this step. This result has been demonstrated by numerous Monte Carlo studies, including: [31]-[33] among others. In light of this encouraging result this study follows [34]-[36] and use the $R B$ based modified- $L R$ statistics to examine the causality between financial deepening and economic growth in Nigeria.

To illustrate the bootstrap modified- $L R$ Granger causality, consider the following bivariate $\operatorname{VAR}(p)$ process:

$$
\begin{gathered}
y_{t}=\Phi_{0}+\Phi_{1} y_{t-1}+\ldots+\Phi_{p} y_{t-p}+\varepsilon_{t}, \\
t=1,2 \ldots, T
\end{gathered}
$$

where ${ }_{t}=\left({ }_{1 t},{ }_{2 t}\right)$ is a white noise process with zero mean and covariance matrix $\Sigma$ and $p$ is the lag order of the process. In the empirical section, the Akaike Information Criterion $(A I C)$ is used to select the optimal lag order $p$. To simplify the representation, $y_{1}$ is partitioned into two sub-vectors, $M 2 G D P$ and $\left(y_{1}\right)$ and $R G D P P C\left(y_{2}\right)$. Hence, rewrite (1) as follows:

$$
\left[\begin{array}{l}
y_{1} \\
y_{2}
\end{array}\right]=\left[\begin{array}{l}
\varphi_{10} \\
\varphi_{20}
\end{array}\right]+\left[\begin{array}{ll}
\varphi_{11}(L) & \varphi_{12}(L) \\
\varphi_{21}(L) & \varphi_{22}(L)
\end{array}\right]\left[\begin{array}{l}
y_{1 t} \\
y_{2 t}
\end{array}\right]+\left[\begin{array}{l}
\varepsilon_{1 t} \\
\varepsilon_{2 t}
\end{array}\right]
$$

where $\phi_{i j}(L)=\sum_{k=1}^{p+1} \phi_{i j, k} L^{k}, i, j=1,2$ and $L$ is the lag operator such that $L^{k} y_{i t}=y_{i t-k}, i=1,2$.

In this setting, the null hypothesis that $R G D P P C$ does not Granger cause $M 2 G D P$ can be tested by imposing zero restrictions $\phi_{12, i}=0$ for $i=1,2, \ldots, p$. In other words, $R G D P P C$ does not contain predictive content, or is not causal, for $M 2 G D P$ if the joint zero restrictions under the null hypothesis:

$$
H_{0}^{M 2 G D P}: \phi_{12,1}=\phi_{12,2}=\ldots=\phi_{12, p}=0
$$

Analogously, the null hypothesis that $M 2 G D P$ does not Granger cause $R G D P P C$ implies that we can impose zero restrictions $\phi_{21, i}=0$ for $i=1,2, \ldots, p$. In this case, $M 2 G D P$ does not contain predictive content, or is not causal, for $R G D P P C$ if the joint zero restrictions under the null hypothesis:

$$
H_{0}^{R G D P P C}: \phi_{21,1}=\phi_{21,2}=\ldots=\phi_{21, p}=0
$$

In the case that both hypotheses in (3) and (4) are rejected the evidence points to bidirectional causality, which in this context implies a feedback system where financial deepening and economic growth react to each other. If only the hypothesis in (3) is rejected, then economic growth Granger causes financial deepening. This implies a unidirectional causality. Analogously, if only the hypothesis in (4) is rejected, financial deepening Granger causes economic growth. It is also possible that neither of the two hypotheses are rejected implying that neither of the two variables has predictive content for the other.

The causality hypothesis in (3) and (4) can be tested using a number of testing techniques. However, this study uses the bootstrap approach pioneered by [37] which uses critical or $p$ values generated from the empirical distribution derived for the particular test using the sample data. In this case, the bootstrap approach is employed to test for Granger non-causality.

Granger non-causality tests assume that parameters of the VAR model used in testing are constant over time. This assumption is often violated because of structural changes and as [38] pointed out, parameter non-constancy is one of the most challenging issues confronting empirical studies today. Although the presence of structural changes can be detected beforehand and the estimations can be modified to address this issue using several approaches, such as including dummy variables and sample splitting, such an approach introduces pre-test bias. Therefore, this study adopts rolling bootstrap estimation in order to overcome the parameter non-constancy and avoid pre-test bias. The details of the method are explained in the Appendix to [34]. To examine the effect of structural changes, the rolling window Granger causality tests, which are also based on the modified bootstrap test, are used. Structural changes shift the parameters and the pattern of the causal relationship may change over time. To deal with structural changes and parameter non-constancy, this paper in addition to full sample estimation, applies the bootstrap causality test to rolling window subsamples for $t=\tau-l+1, \tau-l, \ldots, \tau, t=l, l+1, \ldots, T$, where ${ }_{l}$ is the size of the rolling window.

Further, the parameter values and the pattern of (no) causal relationship may change over time due to structural changes. The results of the Granger causality tests will be sensitive to sample period used and order of the VAR model, if the parameters are temporally instable [34]. Hence, conflicting results for the causal links between financial deepening and economic growth can be found by studies using different sample periods and different VAR specifications. The results of Granger causality tests based on the full sample also become invalid with structural breaks because they assume parameter stability. Therefore, this study tests for parameter stability in the estimated VAR models following [34]-[36]. In practice, a number of tests exist for examining the temporal stability of VAR models [39]-[41]. However, given the non-existence of cointegration between the two series as detailed in the next section, this study employs the Sup-F, 
Ave-F and Exp-F tests developed by [40], [41] to investigate the stability of the short-run parameters.

These tests are computed from the sequence of $L R$ statistics that tests constant parameters against the alternative of a one-time structural change at each possible point of time in the full sample. [40], [41] report the critical values for the non-standard asymptotic distributions of these tests. To avoid the use of asymptotic distributions, the critical values and $p$-values are obtained using the parametric bootstrap procedure. Specifically, the $p$-values are obtained from a bootstrap approximation to the null distribution of the test statistics, constructed by means of Monte Carlo simulation using 2000 samples generated from a VAR model with constant parameters. The Sup-F, Ave-F and Exp-F tests needs to be trimmed at the ends of the sample. Following [40] trimming is done at 15 per cent from both ends and these tests are calculated for the fraction of the sample in $[0.15,0.85]$.

\section{RESULTS}

Table I reports the outcomes of the unit root tests for M2GDP and RGDPPC, with two specifications reported for each of the three tests. The specifications differ in terms of the deterministic components included in the autoregressive function. The first version of every test was conducted with only a constant included, while the second version included a time trend in addition to a constant. The null hypothesis in these tests is that the series are non-stationary (have a unit root) and the tests are performed for the levels (Panel A in Table I) and the first differences (Panel B) of the data. Both series appear to be integrated of the first order, I(1), as is evidenced in Table I, where the null hypothesis is not rejected at conventional critical values for the series in levels, but it's rejected in Panel B where the data has been transformed into first differences.

TABLE I: UNIT ROOT TESTS

\begin{tabular}{|c|c|c|c|c|}
\hline \multicolumn{5}{|c|}{ Panel A. Level } \\
\hline Series & \multicolumn{2}{|c|}{$A D F$} & \multicolumn{2}{|c|}{$P P$} \\
\hline & Constant & $\begin{array}{l}\text { Constant } \\
\text { and Trend }\end{array}$ & Constant & $\begin{array}{l}\text { Constant } \\
\text { and Trend }\end{array}$ \\
\hline RGDPPC & -0.573 & -0.787 & -0.961 & -1.139 \\
\hline$M 2 G D P$ & -2.085 & -2.680 & -1.732 & -2.240 \\
\hline \multicolumn{5}{|c|}{ Panel B. First difference } \\
\hline Series & \multicolumn{2}{|c|}{$A D F$} & \multicolumn{2}{|c|}{$P P$} \\
\hline & Constant & $\begin{array}{l}\text { Constant } \\
\text { and Trend }\end{array}$ & Constant & $\begin{array}{l}\text { Constant } \\
\text { and Trend }\end{array}$ \\
\hline RGDPPC & $-5.042 * * *$ & $-5.057 * * *$ & $-5.079 * * *$ & $-5.014 * * *$ \\
\hline$M 2 G D P$ & $-5.279 * * *$ & $-5.227 * * *$ & $-5.051 * * *$ & $-4.976 * * *$ \\
\hline
\end{tabular}

TABLE II: JOHANSEN COINTEGRATION TEST

\begin{tabular}{llll}
\multicolumn{3}{c}{ TABLE II: JOHANSEN COINTEGRATION TEST } \\
\hline \hline $\mathrm{H}_{0}{ }^{\mathrm{a}}$ & $\mathrm{H}_{1}$ & Trace statistic & $\begin{array}{l}5 \% \text { critical } \\
\text { values }\end{array}$ \\
\hline$r=0$ & $r>0$ & 13.689 & $\begin{array}{l}15.495 \\
3.841\end{array}$ \\
$r \leq 1$ & $r>1$ & 1.070 & \\
\hline $\mathrm{H}_{0}{ }^{\mathrm{a}}$ & $\mathrm{H}_{1}$ & Maximum eigenvalue statistic & $\begin{array}{l}5 \% \text { critical } \\
\text { values }\end{array}$ \\
\hline$r=0$ & $r>0$ & 12.616 & 14.265 \\
$r \leq 1$ & $r>1$ & 1.070 & 3.841 \\
\hline \hline
\end{tabular}

${ }^{a}$ One-sided test of the null hypothesis $\left(\mathrm{H}_{0}\right)$ that the variables are not cointegrated against the alternative $\left(\mathrm{H}_{1}\right)$ of at least one cointegrating relationship.
The Johansen cointegration test results are also presented in Table II. Both the trace and maximum eigenvalue statistics cannot reject the null of no cointegration. This implies that financial deepening and economic growth do not share a long run relationship.

Following these preliminaries the study now proceeds with the investigation of the causal connection between financial deepening and economic growth in Nigeria with the residual based modified-LR tests. As before the optimal lag length is determined with the AIC criteria which determined a lag length of 1 . The two null hypotheses at stake are (a) that financial deepening does not Granger cause economic growth and (b) that economic growth does not Granger cause financial deepening and these will be tested with a full sample bootstrap LR statistic. The results are presented in Table III. The bootstrap LR-test uses the p-values obtained from 2000 replications. Both hypotheses cannot be rejected for the full sample as reported in Table III. Combining these two results suggests no causality over the full sample between financial deepening and economic growth.

TABLE III: FULL SAMPLE BOOTSTRAP GRANGER CAUSALITY TESTS BETWEEN M2GDP AND RGDPPC

\begin{tabular}{llll}
\hline \hline $\begin{array}{l}\mathrm{H}_{0}: M 2 G D P \\
\mathrm{RGDPPC}\end{array}$ & Bootstrap & $L R$-Statistic & $\begin{array}{l}\text { Bootstrap } \\
p \text {-value }\end{array}$ \\
\hline$L R$-Statistic & $p$-value & & $\begin{array}{l}\mathrm{H}_{0}: R G D P P C \\
\text { cause } M 2 G D P\end{array}$ \\
& 0.166 & 0.204 & 0.627 \\
\hline 1.669 & & & \\
\hline
\end{tabular}

At this point the question arises as to the stability of the estimated VAR over the entire sample, and the parameter constancy tests described above were used to test parameter stability for the VAR underlying the causality tests reported in Table IV. Three different tests of short-run parameter stability are reported in Table IV, starting with the M2GDP equation in the first two columns and followed by the $R G D P P C$ equation in turn. In row 1 the Sup-F statistic reports the test of parameter constancy against a one-time sharp shift in parameters. This is followed in rows 2 and 3 by two test statistics Ave-F and Exp-F, which assumes that the parameters follow a martingale process, and test against the possibility that the parameters might evolve gradually. The Ave-F and Exp-F are both optimal tests as shown by [41].

TABLE IV: PARAMETER STABILITY TESTS

\begin{tabular}{|c|c|c|c|c|}
\hline \multirow[t]{2}{*}{ Test } & \multicolumn{2}{|c|}{$M 2 G D P$ Equation } & \multicolumn{2}{|c|}{$R G D P P C$ Equation } \\
\hline & Statistics & $\begin{array}{l}\text { Bootstrap } \\
p \text {-value }\end{array}$ & Statistics & $\begin{array}{l}\text { Bootstrap } \\
p \text {-value }\end{array}$ \\
\hline Sup-F & 3.645121 & 0.22 & 4.116536 & 0.24 \\
\hline Ave-F & 2.022330 & $0.08 *$ & 1.456527 & 0.42 \\
\hline $\operatorname{Exp}-F$ & 1.109157 & $0.09 *$ & 0.831302 & 0.45 \\
\hline
\end{tabular}

Notes: * denotes significance at 10 percent. ${ }^{a} p$-values are calculated using 2000 bootstrap repetitions.

The Ave-F, and Exp-F tests report evidence of parameter instability in the M2GDP equation. The evidence in Table IV suggests a gradual evolution of the parameters in the M2GDP equation. Parameter instability of the kind identified here would undermine traditional Granger causality tests of the connection between financial deepening and economic growth. One would expect that the Granger causality tests would be sensitive to sample period changes in this case and 
it might help explain why studies have found such conflicting evidence on the causal nature of the relationship for the same country.

Accordingly the paper proceeds to investigate the dynamic causal link between financial deepening and economic growth with rolling window regression techniques. The rolling window estimators, also known as fixed-window estimators, are based on a changing subsample of fixed length that moves sequentially from the beginning to the end of sample by adding one observation at the end of the sample while dropping one at the start. A window size of $l$ means that each rolling subsample includes $l$ observations. For every window the causality test is repeated using the residual based bootstrap method which yields a sequence of $T-l$ causality tests.

An important choice parameter in rolling estimations is the window size $l$ which controls the number of observations covered in each subsample as well as the total number of rolling estimates. More importantly, the precision and representativeness of the subsample estimates are controlled by the window size. A large window size increases the precision of estimates, but may reduce the representativeness, particularly, in the presence of heterogeneity. On the other hand, a small window size will reduce heterogeneity and increase representativeness of the parameters, but it may increase the standard error of estimates [34]. The challenge is to a select a window size along this trade-off between precision and representativeness. Following [34] and [42], this paper uses a rolling window of small size to guard against heterogeneity. See [43] for simulation results on choice of window size. The choice of small window size may lead to imprecise estimates. Therefore, the bootstrap technique is applied to each subsample estimation so as to improve the accuracy of the parameter estimates and raise the power of inferential tests.

The selection of window size in rolling window estimation has no strict criterion. [43] examined the window size under structural change in terms of root mean square error. They show that optimal window size depends on persistence and the size of the structural breaks in the series. In determining the window size, we need to balance between two conflicting demands. First, the accuracy of parameter estimates which depends on the degree of freedom and requires a larger window size for higher accuracy. Second, the presence of multiple regime shifts increases the probability of including some of these multiple shifts in the windowed sample. To reduce the risk of including multiple shifts in the subsamples, the window size needs to be small. Based on the simulation results in [43] a window size of 10 (this excludes the observations required for lags and hence is the actual number of observations in the VAR) is used. The bootstrap $p$-value of observed $L R$-statistic rolling over the whole sample period 1961-2012 is estimated in order to further examine the likely temporal changes in the causality relationship. To do this, the VAR model in (1) is estimated for a time span of 10 years rolling through $t=\tau-9, \tau-8, \ldots, \tau, \tau=10, \ldots, T$ and calculate the bootstrap p-values using the residual based method explained in the appendix to [36] for the two null hypotheses (a) that $M 2 G D P$ does not Granger cause
$R G D P P C$ and (b) that $R G D P P C$ does not Granger cause $M 2 G D P$. More precisely, the residual based $p$-values of the modified $L R$-statistics that tests the absence of Granger causality from $M 2 G D P$ to $R G D P P C$ or vice-versa is computed. These are computed from the VAR defined in (2) fitted to a rolling window of with 10 observations.

The plots of the bootstrap $p$-values of the rolling test statistics are given in Fig. 2 and Fig. 3, with the horizontal axes showing the final observation in each of the 10-year rolling windows. The bootstrap p-values in Fig. 2 and Fig. 3, suggest that there are significant changes in causal links between the series over this sample. Fig. 2 shows the bootstrap $p$-values of the rolling test statistics, testing the null hypothesis that financial deepening does not Granger-cause economic growth. The non-causality tests are evaluated at 10 per cent significance level. Fig. 2 shows that the null hypothesis that financial deepening does not Granger-cause economic growth is rejected at 10 per cent significance level in the sub periods 1973-1974 and 1976.

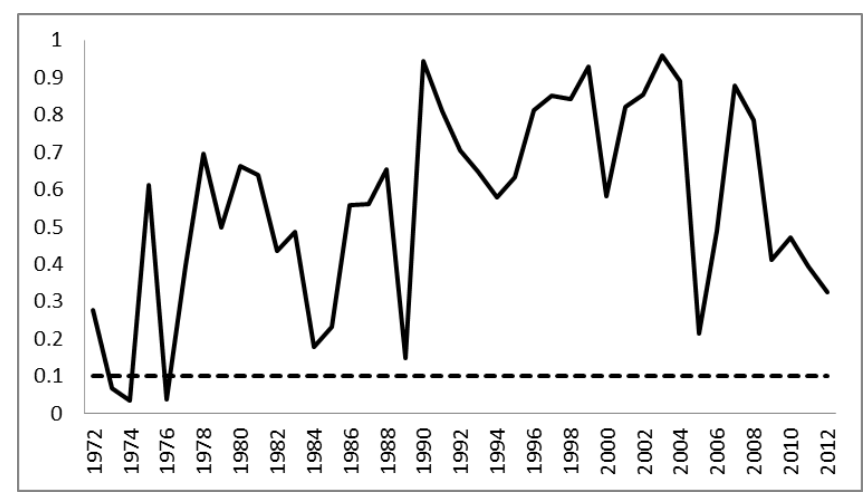

Fig. 2. Bootstrap $p$-values of $L R$ test statistic testing the null hypothesis that financial deepening does not Granger cause economic growth.

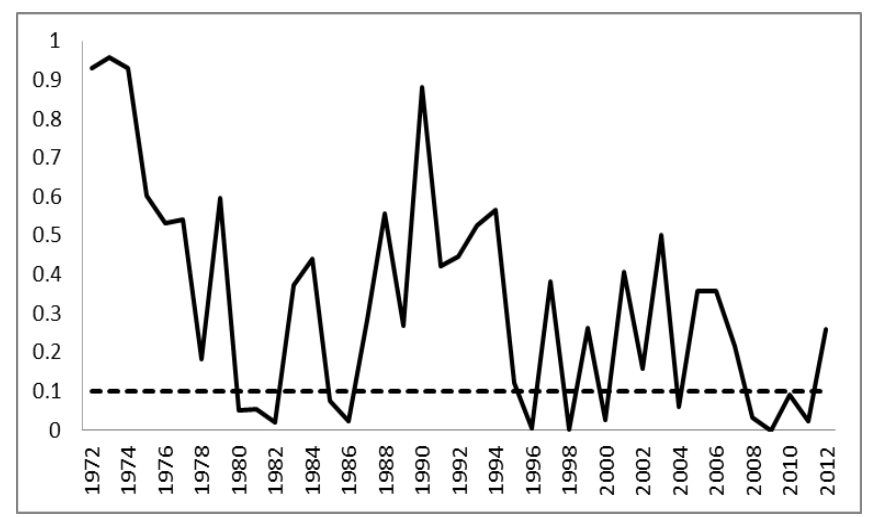

Fig. 3. Bootstrap $p$-values of $L R$ test statistic testing the null hypothesis that economic growth does not Granger cause financial deepening.

\section{CONCLUSION}

This paper contributes to the growing literature on the finance-economic growth relationship using the bootstrap rolling window approach. The case for Nigeria is re-investigated using annual data on the ratio of $\mathrm{M} 2$ to nominal GDP and real GDP per capita from 1961-2012. By contrast with previous studies on the dynamic relationship between financial deepening and economic growth, this study use both full sample bootstrap Granger causality tests 
and bootstrap rolling window tests with fixed sample size, which allows inference without considering whether the series are integrated-cointegrated. Based on the results of full sample bootstrap Granger causality tests, financial deepening has no predictive power for economic growth and economic growth also has no predictive power for financial deepening. However, using parameter stability tests, results show that the $M 2 G D P$ equation is unstable for the full sample, undermining the inference drawn from full-sample Granger causality tests. Using the bootstrap rolling window estimation, it is shown that at 10 per cent level of significance, financial deepening and economic growth have predictive power for each other, although economic growth has more prolonged and current effect on financial deepening spanning the 1980 s to 2011 sub periods. The results point to the need for Nigeria to strengthen its financial system. Finance-related policies should work on consolidating finance-growth links in more holistic ways. For instance, better macroeconomic stability or improved institutional quality, investment in physical and human capital may influence financial deepening favourably. Through this, the development of financial systems in Nigeria may gradually correspond more adequately to real sector activities, consequently facilitating economic growth. These results also indicate that the causal relation between $M 2 G D P$ and $R G D P P C$ is episodic, asymmetric and time varying. Therefore, these properties need to be taken into account in any analysis relating to these series to avoid misleading policy conclusions.

\section{REFERENCES}

[1] Central Bank of Nigeria, "Statistical bulletin," vol. 1, no. 4, pp. 1-215, 2012.

[2] Trading Economics. (2014). Nigeria GDP Annual Growth Rate. [Online]. Available: http://www.tradingeconomics.com/nigeria/gdp-growth-annual

[3] Central Bank of Nigeria, "Integrating financial services into poverty reduction strategies: - institutional experience of Nigeria," in Proc. the West Africa Sub Regional Workshop, Bolingo hotel \& Towers, Abuja, Nigeria, September 13-15, pp. 1-33, 2005.

[4] J. A. Schumpeter, "Theorie der wirtschaftlichen entwicklung," The Theory of Economic Development, Leipzig: Dunker \& Humblot, translated by R. Opie., Cambridge, MA: Harvard University Press, 1912.

[5] J. Robinson, "The generalization of the general theory," The Rate of Interest, and other Essays, Macmillan, London, pp. 1-180, 1952.

[6] T. Gries, M. Kraft and D. Meierrieks, "Financial deepening, trade openness and economic growth in Latin America and the Caribbean," Applied Economics, vol. 43, no. 30, pp. 4729-4739, 2011.

[7] M. Pagano, "Financial markets and growth: an overview," European Economic Review, vol. 37, no. 2-3, pp. 613-622, 1993.

[8] R. G. King and R. Levine, "Finance, entrepreneurship, and growth," Journal of Monetary Economics, vol. 32, no. 3, pp. 513-542, 1993.

[9] J.-C. Berthelemy and A. Varoudakis, "Economic growth, convergence clubs, and the role of financial development," Oxford Economic Papers, vol. 48, no. 2, pp. 300-328, 1996.

[10] R. E. Lucas, "On the mechanics of economic development," Journal of Monetary Economics, vol. 22, no. 1, pp. 3-42, 1988.

[11] J. Zhuang, H. Gunatilake, Y. Niimi, M. E. Khan, Y. Jiang, R. Hasan, N. Khor, A. S. Lagman-Martin, P. Bracey, and B. Huang, "Financial sector development, economic growth, and poverty reduction: A literature review," ADB Economics Working Paper Series, no. 173, 2009.

[12] N. M. Odhiambo, "Finance-growth-poverty nexus in South Africa: A dynamic causality linkage," The Journal of Socio-Economics, vol. 38 , no. 2, pp. 320-325, 2009.

[13] S. Olofin and U. J. Afangideh, "Financial structure and economic growth in Nigeria," Nigerian Journal of Securities and Finance, vol. 13, no. 1, pp. 47-68, 2008.
[14] S. O. Odeniran and E. A. Udeaja, "Financial sector development and economic growth: Empirical evidence from Nigeria," Central Bank of Nigeria Economic and Financial Review, vol. 48, no. 3, pp. 91-124, 2010.

[15] S. O. Fadare, "Recent banking sector reforms and economic growth in Nigeria," Middle Eastern Finance and Economics, issue 8, pp. 146-160, 2010.

[16] A. O. Adenuga, "Stock market development indicators and economic growth in Nigeria (1990-2009)," Central Bank of Nigeria Economic and Financial Review, vol. 48, no. 1, pp. 33-70, 2010.

[17] A. Ujunwa and O. P. Salami, "Stock market development and economic growth: Evidence from Nigeria," European Journal of Economics, Finance and Administrative Sciences, issue 25, pp. 44-53, 2010.

[18] G. C. Aye, "The Causality between financial development and agricultural growth in Nigeria," Global Business and Economics Anthology, vol. 2, pp. 114-119, 2012.

[19] G. C. Aye, "Causality between financial deepening, economic growth and poverty in Nigeria," Business and Management Review, vol. 3, no. 3 , pp. 1-12, 2013.

[20] A. I. Shittu, "Financial intermediation and economic growth in Nigeria," British Journal of Arts and Social Sciences, vol. 4, no. 2, pp. 164-179, 2012.

[21] C. Hsiao, "Autoregressive modelling of Canadian money and income data," Journal of the American Statistical Association, vol. 74, no. 367, pp. 553-560, 1979.

[22] C. Hsiao, "Autoregressive modelling and causal ordering of economic variables," Journal of Economic Dynamics and Control, vol. 4, no. 1, pp. 243-259, 1982.

[23] P. C. Phillips, "Time series regression with a unit root," Econometrica, vol. 55, no. 2, pp. 277-301, 1987.

[24] P. C. Phillips and P. Perron, "Testing for a unit root in time series regression," Biometrika, vol. 75, no. 2, pp. 335-346, 1988.

[25] S. Ng. and P. Perron, "Lag length selection and the construction of unit root tests with good size and power," Econometrica, vol. 69, no. 6, pp. 1519-1554, 2001.

[26] J. P. Park and P. C. B. Phillips, "Statistical inference in regression with integrated process: Part 2," Econometric Theory, vol. 5, no. 1, pp. 95-131, 1989

[27] H. Y. Toda and P. C. B. Phillips, "Vector autoregressions and causality," Econometrica, vol. 61, no. 6, pp. 1367-1393, 1993.

[28] H. Y. Toda, and P. C. B. Phillips, "Vector autoregression and causality: a theoretical overview and simulation study," Econometric Reviews, vol. 13, no. 2, pp. 259-285, 1994

[29] H. Y. Toda and T. Yamamoto, "Statistical inference in vector autoregressions with possibly integrated processes," Journal of Econometrics, vol. 66, no. 1-2, pp. 225-250, 1995.

[30] J. J. Dolado and H. Lütkepohl, "Making Wald tests work for cointegrated VAR system," Econometrics Reviews, vol. 15, no. 4, pp. 369-386, 1996.

[31] J. L. Horowitz, "Bootstrap-based critical values for the information matrix test," Journal of Econometrics, vol. 61, no. 2, pp. 395-411, 1994.

[32] G. Shukur and P. Mantalos, "A simple investigation of the Granger-causality test in integrated-cointegrated VAR systems," Journal of Applied Statistics, vol. 27, no. 8, pp. 1021-1031, 2000.

[33] R. S. Hacker and A. J. Hatemi, "Tests for causality between integrated variables based on asymptotic and bootstrap distributions: theory and application," Applied Economics, vol. 38, no. 13, pp. 1489-1500, 2006.

[34] M. Balcilar and Z. A. Ozdemir, "The export-output growth nexus in Japan: a bootstrap rolling window approach," Empirical Economics, vol. 44, no. 2, pp. 639-660, 2013.

[35] M. Balcilar and Z. A. Ozdemir and Y. Arslanturk, "Economic growth and energy consumption causal nexus viewed through a bootstrap rolling window," Energy Economics, vol. 32, no. 6, pp. 1398-1410, 2010.

[36] G. C. Aye, M. Balcilar, J. P. Dunne, R. Gupta, and R. van Eyden "Military expenditure, economic growth and structural instability: A case study of South Africa," To be published in Defence and Peace Economics.

[37] B. Efron, "Bootstrap methods: Another look at the jackknife," Annals of Statistics, vol. 7, no. 1, pp. 1-26, 1979.

[38] C. W. J. Granger, "Can we improve the perceived quality of economic forecasts?" Journal of Applied Econometrics, vol. 11, no. 455-73, 1996.

[39] B. E. Hansen, "Tests for parameter instability in regressions with I(1) processes," Journal of Business and Economic Statistics, vol. 10, no. 3, 321-335, 1992. 
[40] D. W. K. Andrews, "Tests for parameter instability and structural change with unknown change point," Econometrica, vol. 61, no. 4, pp. 821-856, 1993.

[41] D. W. K. Andrews and W. Ploberger, "Optimal tests when a nuisance parameter is present only under the alternative," Econometrica, vol. 62 , no. 6, pp. 1383-1414, 1994.

[42] A. Koutris, M. S. Heracleous, and A. Spanos, "Testing for nonstationarity using maximum entropy resampling: a misspecification testing perspective," Econometric Reviews, vol. 27, no. 4-6, pp. 363-384, 2008.

[43] M. H. Pesaran and A. Timmermann, "Small sample properties of forecasts from autoregressive models under structural breaks," Journal of Econometrics, vol. 129, no. 1-2, pp. 183-217, 2005.

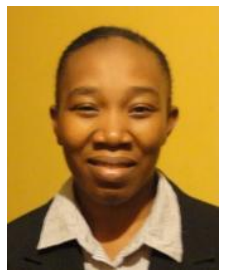

Goodness C. Aye obtained her Ph.D in agricultural economics from University of Pretoria, South Africa. She lectures at University of Agriculture, Makurdi, Nigeria. She is also researcher fellow at University of Pretoria, South Africa. She has over 50 publications in form of books, peer reviewed journals and conference proceedings covering micro and macroeconomic policy analysis, agricultural development and policy analysis, production economics, environmental economics, energy economics, and poverty studies. She has served as reviewer to several reputed journals. She is a member of several professional organisations including Golden Key International Society, Agricultural and Applied Economics Association (AAEA), Australian Association of Agricultural and Resources Economics (AARES) and Nigerian Association of Agricultural Economists (NAEE) among others. Dr. Aye has received a number of awards and fellowships including Council for the Development of Social Science Research in Africa (CODESRIA) Small Grant for Thesis Writing, ANSTI/DAAD UNESCO Postgraduate Fellowship, MMMF World Bank Postgraduate Fellowship and University of Pretoria academic colors for academic achievement among others. 